\section{Putting an End to It!}

OK, I know that's a frivolous title for a serious subject. But I wanted to get your attention. I've been thinking a lot about physician-assisted suicide. It's big news here in California right now because Governor Brown just signed a bill legalizing this practice. Californians have resisted this in the past, but things have changed. The recent case of Brittany Maynard, the young woman with brain cancer who moved to Oregon so she could die on her own terms and who publicly discussed her journey in great detail, has catalyzed this for many Californians. California is now the fifth state to legalize euthanasia.

In preparing to put my thoughts about this on paper, I did some homework. Using my trusted Google Scholar, I searched for scholarly publications on legalized euthanasia. You know what? There are very, very few and almost none in the past decade. You'd think that such an important topic would warrant a little attention-from the behavioral scientists, if no one else. Is this topic too delicate or too political to study with scientific rigor? Maybe it is.

I did find an opinion piece in The New England Journal of Medicine published in $2013 .{ }^{1}$ The authors discuss the case of a man with metastatic pancreatic cancer (that strikes close to home!) who is receiving good palliative care but is inquiring about physician-assisted suicide. Conveniently, he lives in Oregon.

Two of the 3 authors take the "con" position, noting that a physician's role is to heal, including the provision of effective palliative care. They assert that legalizing euthanasia creates a slippery slope that leads easily to expanded access or abuse. They also note that, in Oregon, where the Death with Dignity Act requires an annual report, physicians are present at less than 10\% of assisted deaths, suggesting that in some way-perhaps on moral grounds - they are distancing themselves from the final event.

The third author takes the "pro" position. She maintains that assisted suicide might be considered an aspect of palliative care and that respecting a patient's desire to end life on his or her own terms, and assisting in that process, can be compatible with the ethos of medicine. Although, of course, she states that the task of enabling suicide cannot be forced on physicians and must be left to each individual's conscience.

I believe that, for patients, this question is not as much about ending suffering as about autonomy and control. I can honestly say that in my many years of caring for the terminally ill, I don't recall anyone who asked for my help to die. That makes me wonder who is helping these patients who chose suicide, at least the ones with cancer, who are reported to be the major patient group taking this option.

And what about the patients? Are these the patients, when faced with a terminal diagnosis, so fearful of future pain and suffering that they avoid established medicine altogether and simply "opt out?" I recognize that the public can have a twisted notion of what the journey is like for a patient with cancer. Maybe some are simply too scared "to go there."

I'd also like to know more about what health care providers are participating in assisted suicide. Are they competent caregivers who help patients explore all the options? I hope so. And I know safeguards are supposed to be in place (comprehensive screening, informed consent), but are we sure they work the way they're supposed to?

I suppose you are wondering about my own position on this. I believe that as a healer, I could never actively end someone's life. I feel we all have some mission, whether we understand it or not, and that each day we breathe is a day we can contribute to a better world. It may be as simple as a smile or a kind word to someone who needs it. Even a person on their deathbed can do that.

But I know opinions vary, and I respect that. What do you think? Let me know.

\section{Reference}

1. Boudreau JD, Somerville MA, Biller-Andorno N. Clinical decisions. Physician-assisted suicide. N Engl J Med 2013;368:1450-1452.

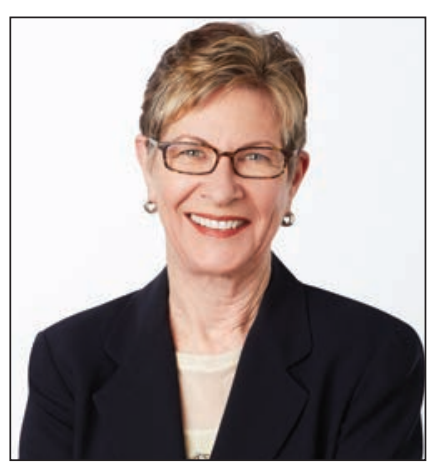

Margaret Tempero, MD

Dr. Tempero is a Professor of Medicine and Director of the UCSF Pancreas Center, and the editorin-chief of JNCCN. Her research career has focused on pancreatic ductal adenocarcinoma, especially in the area of investigational therapeutics.

Dr. Tempero has served on the ASCO Board of Directors and as ASCO President. She co-directed the AACR/ASCO Methods in Clinical Cancer Research and taught this course and similar courses in Europe and Australia. She was founding Chair of the $\mathrm{NCl}$ Clinical Oncology Study Section (CONC) and served as a member and chair of the $\mathrm{NCl}$ Board of Scientific Counselors Subcommittee A. She is on the External Advisory Boards of the Pancreas SPOREs at Mayo Clinic and at UAB/Minnesota and the GI SPORE at the University of Arizona. She is, or has been, on the Scientific Advisory Boards of the Lustgarten Foundation, the Pancreatic Cancer Action Network, the V Foundation, The Alberta Canada Cancer Board, and the EORTC. She served as a member of the Oncology Drug Advisory Committee for the FDA. She has served as Deputy Director and Interim Director for the UNMC Eppley Cancer Center. She is Chief Emeritus of the Division of Medical Oncology at UCSF and served as Deputy Director and Director of Research Programs at the UCSF Helen Diller Family Comprehensive Cancer Center.

The ideas and viewpoints expressed in this editorial are those of the author and do not necessarily represent any policy, position, or program of NCCN. 